\title{
Effect of Operating Parameters on Extraction of Oil from Bitter Gourd Seeds: A Kinetic and Thermodynamic Study
}

\author{
P. Umamaheshwari, P. Dinesh Sankar Reddy*
}

Department of Chemical Engineering, JNTUA College of Enineering (Autonomous), Anantapuramu

\begin{abstract}
Bitter gourd (Momordicacharantia) is a very nutritious vegetable having high therapeutic value due to the presence of $\alpha$ Eleostearic acid and exhibits anti carcinogenic properties. Present study involves extraction of oil from bitter gourd seeds using soxhlet apparatus with n-hexane as a solvent. The effect of extraction time, volume of solvent and particle size of bitter guard on oil yield was estimated and observed that, the oil yield has increased with increase in time and volume of solvent but decreased with increase in particle size. It was also observed that, a maximum oil yield of $51 \%$ was obtained at $100^{\circ} \mathrm{C}$ for an extraction time of 150 minutes using $15 \mathrm{~g}$ of dried Bitter Gourd seed and $50 \mathrm{ml}$ of n-hexane. Apart from these, the kinetics and thermodynamics of oil extraction from bitter gourd seeds was also studied. The kinetic studies have shown that the extraction process has fourth order kinetics and the thermodynamic studies reveal that the process is endothermic and requires energy.
\end{abstract}

Keywords: Kinetics, Thermodynamics, Solvent Extraction, Bitter gourd, n-Hexane

\section{Introduction}

Momordicacharantia L.,commonly referred as bitter gourd, Karela, bitter melon, or balsam pear belongs to the Cucurbitaceae family [1]. It is a tropical plant that is widely cultivated in Asia, East Africa and South America [2,3]. The immature fruits of bitter gourd are a good source of Vitamin $\mathrm{C}$, Vitamin A, phosphorus and iron and are rich in minerals including $\mathrm{K}, \mathrm{Ca}, \mathrm{Zn}$ and $\mathrm{Mg}$ [4,5]. Biologically, it has a good source of dietary fiber. It is used in folkloric medicine for treatment of various ulcers, diabetes, infections $[6,7,8]$, gout [9], wounds, infections, parasites (e.g., worms), hepatitis and fevers. Also, it is extensively used in paints, coatings and inks.

There are various techniques such as mechanical, solvent, traditional and super critical fluid extraction methods to obtain the oil from the seeds. Among these methods solvent extraction has become popular for easy and high percentage of oil recovery from seeds. Further, mechanical extraction produces oil with high turbidity and water content and supercritical fluid extraction is very expensive to build and maintain. The solvent, n-Hexane is often used for oil extraction because of its lower boiling point, non-polar nature for easy separation after extraction and it has low toxicity. The yield \% of oil obtained by using $n$-hexane is high compared with ethanol from neem [10]. Several parameters such as particle size, volume of solvent, operating temperature and extraction time has been found to affect the percentage yield of oil from seeds. Hence, the determination of the effects of these parameters on oil yields from seeds is important to minimize the loss of oil, amount of energy expanded over time and finally the cost of extraction. The present study involved extraction of oil from bitter gourd seeds using n-Hexane, determining the effect of time, volume of solvent and particle size on the percentage yield of oil and in detail the kinetic and thermodynamic properties of oil.

\section{Materials and Methods}

\subsection{Seed Collection and Preparation}

Commercially available bitter melon seeds were bought from local market and washed thoroughly with distilled water to remove dirt, dust and the pesticide residue. The seeds were then dehulled and subsequently dried in a tray drier at $60^{\circ} \mathrm{C}$ until a constant weight of seeds is obtained [11]. The dried seeds were cooled and ground using a grinding machine and sieved through different Tyler screens to obtain average particle sizes of $1.303 \mathrm{~mm}, 0.9545 \mathrm{~mm}, 0.564 \mathrm{~mm}, 0.358 \mathrm{~mm}$ and $0.253 \mathrm{~mm}$. The samples were stored in separate air tight containers and labeled adequately.

\subsection{Solvent Extraction}

A determined quantity of n-Hexane was taken in a Soxhlet extractor. The weight of $12.0024 \mathrm{~g}$ of bitter gourd seed on Whatman No.1 filter paper was placed in the thimble of the Soxhlet extractor. The condenser ensures that the solvent vapor cools and drips back down into the chamber housing the solid material. The heating mantle was set at a specified temperature for the experiment and the extraction was carried out for a given time. After the extraction of oil with n-hexane, the set up was dismantled and the miscella (mixture of n-hexane and Bitter gourd oil) obtained was poured into the distillation flask placed on the heating mantle. The heating mantle was set at $68^{\circ} \mathrm{C}$ which is the boiling point of pure hexane. After distillation, the weight of the oil was determined. The effect of various parameters like time, amount of solvent and particle size on oil yield was estimated during the extraction process.

$$
\% \text { Yield }(\mathrm{Y})=\frac{\text { weight of pureoil extracted }(\mathrm{g})}{\text { weight of the initial sample }(\mathrm{g})} \mathrm{X} 100
$$




\section{International Journal of Science and Research (IJSR) \\ ISSN (Online): 2319-7064}

Index Copernicus Value (2013): 6.14 | Impact Factor (2014): 5.611

\subsection{Kinetics Studies}

The kinetic parameters are calculated by studying the effect of time on the extraction process which are related by the

$$
\text { equation, }(d Y / d t)=\mathrm{kY}^{\mathrm{n}}
$$

Where $\mathrm{Y}$ is percentage oil yield; $\mathrm{t}$ is time of extraction (min); $\mathrm{k}$ is extraction constant; and $\mathrm{n}$ is the reaction order. The plot of $\ln (\mathrm{dY} / \mathrm{dt})$ and $\ln \mathrm{Y}$ gives a straight line, the slope of which gives the order of the reaction $n$ and the intercept gives the $\ln (\mathrm{k})$ value [12].

\subsection{Thermodynamics}

Thermodynamic parameters for Bitter gourd oil extraction were determined using the following equation.

$$
\begin{gathered}
\ln k=\frac{-\Delta G}{R T}=\frac{-\Delta H}{R} \cdot \frac{1}{T}+\frac{\Delta S}{R} \\
k=\left(Y_{T} / Y_{u}\right)
\end{gathered}
$$

Where $\mathrm{K}$ is the equilibrium constant; $\mathrm{Y}_{\mathrm{T}}$ is the percent oil yield at temperature $\mathrm{T} ; \mathrm{Y}_{\mathrm{u}}$ is the percent un-extracted oil; $\Delta \mathrm{H}$ is the enthalpy change $(\mathrm{k} . \mathrm{J} / \mathrm{mol}) ; \Delta \mathrm{S}$ is the entropy change (k.J/mol.K); $\Delta \mathrm{G}$ is the free energy or Gibb's energy (k.J/mol), R is Universal gas constant $(8.314 \mathrm{k} . J / \mathrm{K} . \mathrm{mol})$ and $\mathrm{T}$ is Temperature (K). From eq. 4 , the plot between lnk versus $1 / \mathrm{T}$ gives straight line and the slope of the line gives $-\Delta H / R$ and intercept gives $\Delta \mathrm{S} / \mathrm{R}$. These values are used in calculating the value of $\Delta \mathrm{H}, \Delta \mathrm{S}$ and $\Delta \mathrm{G}$.

\section{Results and Discussion}

The current work is mainly focused on study on various factors affecting the \% yield of oil extraction using n-hexane as solvent.

\subsection{Effect of Volume of Solvent}

The effect of solvent volume was studied by keeping other variables like particle size, time of extraction and temperature as constant. The $\%$ yield of oil at different volumes of solvent was estimated and found that as the volume of solvent increased from $10 \mathrm{ml}$ to $50 \mathrm{ml}$, the $\%$ yield is also increased from $15 \%$ to $27 \%$. The maximum yield of $27 \%$ was obtained at a solvent volume of $50 \mathrm{ml}$.

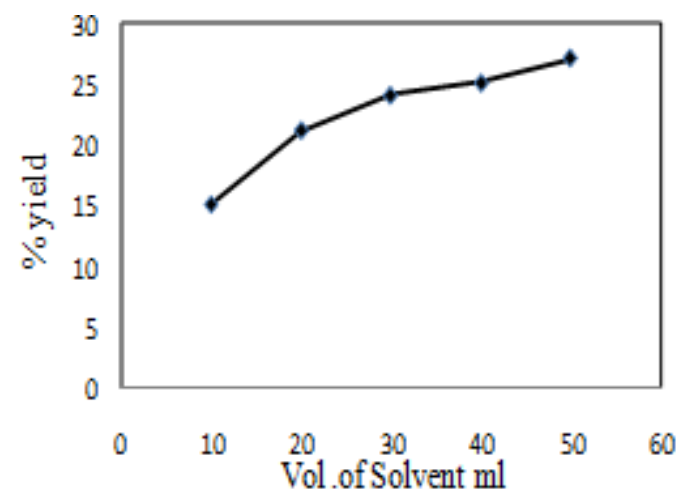

Figure 1: Effect of volume of solvent on \% yield of oil extraction

\subsection{Effect of Particle Size}

The yield percentage of oil has increased with decreasing particle size. The experimental results shown that as the size of the particle decreased from $1.303 \mathrm{~mm}$ to $0.253 \mathrm{~mm}$, the yield $\%$ of oil increased from 13 to $31 \%$. Therefore, lower particle size influenced and increased the extraction $\%$ yield of Bitter gourd oil.

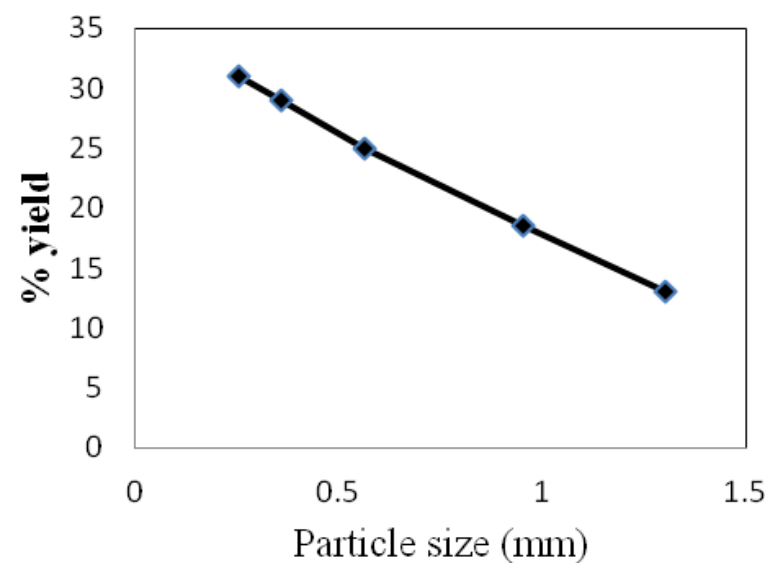

Figure 2: Effect of particle size on \% yield of oil extraction

\subsection{Effect of Temperature}

The \% yield of oil extracted from Bitter gourd seeds at different Temperature conditions are shown in the Fig 3.

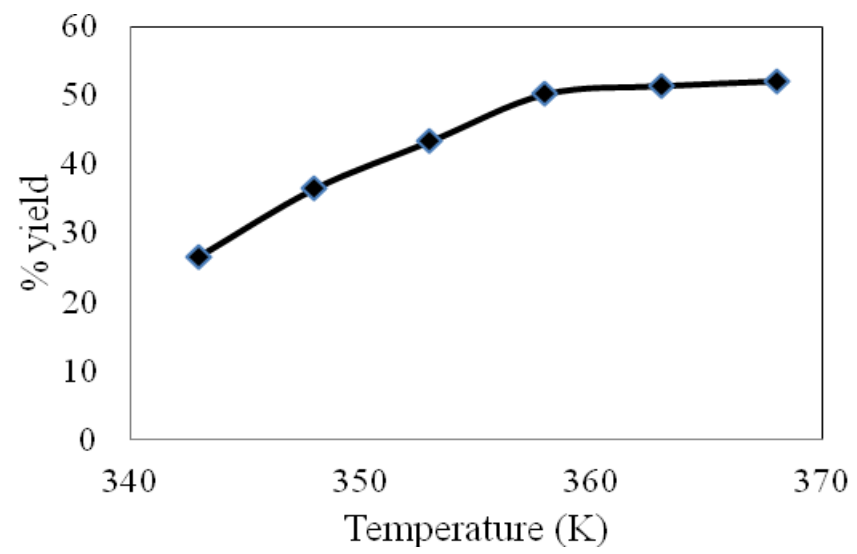

Figure 3: Effect of Temperature of solvent on \% of yield of oil extraction

When the temperature was increased from $343 \mathrm{~K}$ to $368 \mathrm{~K}$, the $\%$ yield also increases accordingly from $26.5 \%$ to $52.1 \%$. The $\%$ yield of bitter gourd oil increased up to $358 \mathrm{~K}$, after that there is no remarkable increase and the \% yield of bitter gourd oil remains nearly constant. In this study, a maximum value of $52.1 \%$ of oil yield was obtained at a temperature of $368 \mathrm{~K}$.

\subsection{Effect of Extraction Time}

The yield of oil increased with time as the extraction process was carried out at a constant temperature of 308K (ambient temperature) and with $50 \mathrm{ml}$ of solvent. The processing time is varied between 30 to $150 \mathrm{~min}$ with an interval of $30 \mathrm{~min}$. The plot between \% yield and time showed that the \% oil yield increases with time. The amount of extracted oil by nhexane did not change significantly after $90 \mathrm{~min}$. A 
maximum of $29.42 \%$ oil yield is achieved after 150 minutes of extraction.

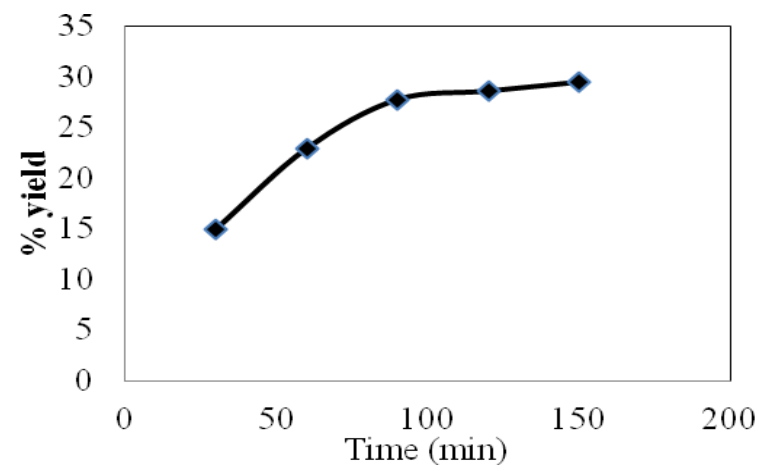

Figure 4: Effect of time on \% of yield for Bitter gourd oil extraction

\subsection{Kinetic Study}

The plot between $\ln (\mathrm{dY} / \mathrm{dt})$ and $\ln \mathrm{Y}$ resulted in a straight line. The process of extraction of oil from Bitter gourd has displayed a fourth order kinetics as observed from the slope of the line and its intercept was used to determine the reaction rate constant as $9.433 \mathrm{~min}^{-1}$

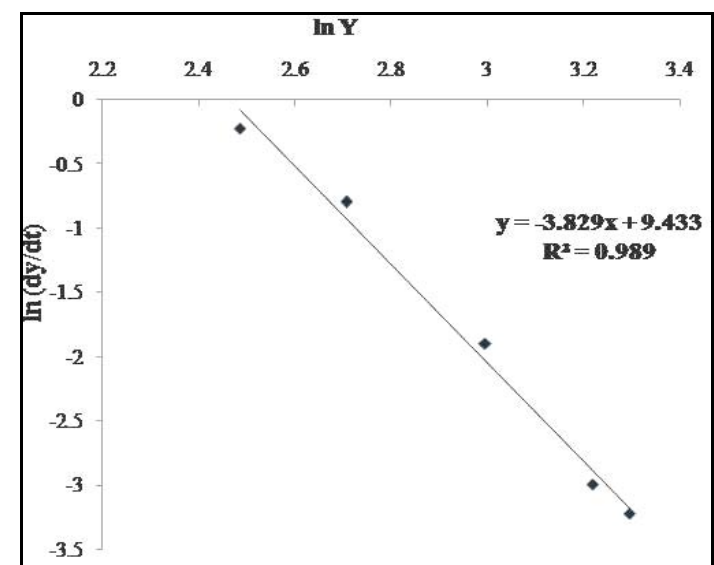

Figure 5: A plot between $\ln (\mathrm{dY} / \mathrm{dt})$ vs $\ln \mathrm{Y}$ for oil extraction

\subsection{Thermodynamic Study}

A plot of $\operatorname{lnK}$ and 1/T is as shown in Fig.6. From the slope of the plot enthalpy change $(\Delta \mathrm{H})$ of the process was calculated as $11.70 \mathrm{KJ} / \mathrm{mol}$. This indicates that the process is endothermic and required energy during the extraction process. An intercept of 3.228 was obtained from which the entropy change of $0.26 \mathrm{KJ} / \mathrm{mol} \mathrm{K}$ was calculated. The Gibbs free energy calculated at various temperatures is shown in Table 1. The negative values of Gibbs energy indicate that the process is spontaneous in nature and it is feasible.

Table 1: Equilibrium constant $(\mathrm{K})$ and Gibbs free energy $(\Delta \mathrm{G})$ at various Temperatures

\begin{tabular}{|c|c|c|}
\hline $\begin{array}{c}\mathrm{T} \\
(\mathrm{K})\end{array}$ & $\begin{array}{c}\mathrm{K} \\
\mathrm{min}^{-1}\end{array}$ & $\begin{array}{c}\Delta \mathrm{G} \\
(\mathrm{KJ} / \mathrm{mol} . \mathrm{K})\end{array}$ \\
\hline 343 & 0.418 & -2.487 \\
\hline 348 & 0.443 & -2.356 \\
\hline 353 & 0.46 & -2.279 \\
\hline 358 & 0.496 & -2.087 \\
\hline 363 & 0.524 & -1.95 \\
\hline
\end{tabular}

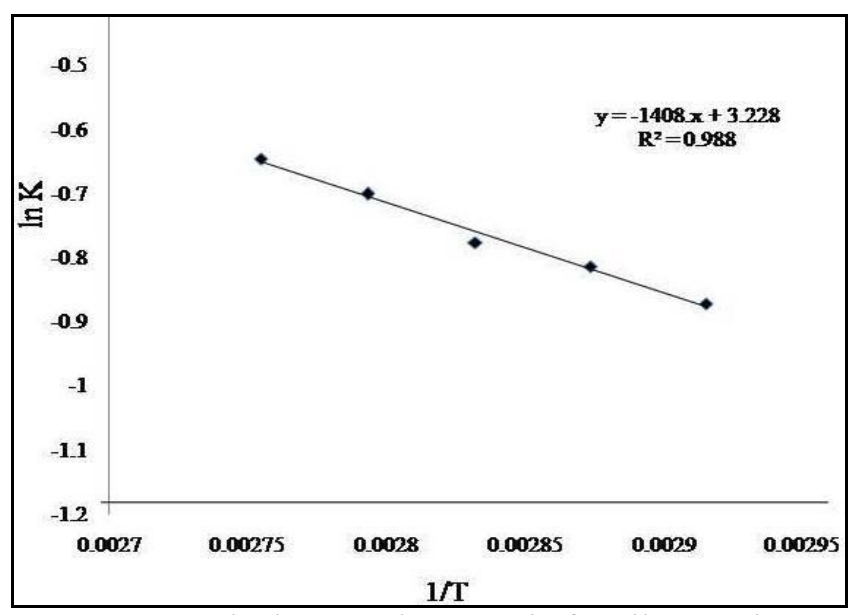

Figure 6: Plot between $\ln \mathrm{K}$ vs $1 / \mathrm{T}$ for oil extraction

\section{Conclusion}

In this study n-Hexane was used for oil extraction from bitter gourd seeds. The obtained results show that there is a remarkable effect of parameters like volume of solvent, particle size, extraction time and temperature on extraction of oil. It was also observed that, a maximum oil yield of $51 \%$ was obtained at $100^{\circ} \mathrm{C}$ for an extraction time of 150 minutes using $15 \mathrm{~g}$ of dried Bitter Gourd seed and $50 \mathrm{ml}$ of $\mathrm{n}$-hexane. The estimation of kinetic studies concluded that the bitter gourd seed oil extraction process has fourth order kinetics. The thermodynamic studies reveal that the process is endothermic and required energy, as a positive value of enthalpy change $(\Delta \mathrm{H}=11.70 \mathrm{~kJ} / \mathrm{mol})$ was obtained. The positive value of entropy change $(\Delta \mathrm{S}=0.26 \mathrm{~kJ} / \mathrm{mol} \mathrm{K})$ indicates that the process is irreversible and it can be inferred that the process is feasible and spontaneous in nature as Gibbs energy at various temperatures was negative.

\section{Acknowledgments}

The authors are grateful to Mr. N. Yasovardhan for his support in documenting this paper. The authors are also grateful to Mr. Gopal Krishna and Mrs. Padmaja, lecturers, JNTUA- OTRI, Anantapur, (A.P) for their kind support for the experimental work.

\section{References}

[1] H.L. Chakravarty, "Cucurbits of India and their role in the development of vegetable crops in Biology and Utilization of Cucurbitaceae," Journal of Biological Sciences, (3), pp. 1134-1139, 1990.

[2] W.T. Cefalu, J. Ye, Z.Q. Wang, "Efficacy of dietary supplementation with botanicals on carbohydrate metabolism in humans," Endocr Metab Immune Disord Drug Targets, (8), pp. 78-81, 2008.

[3] G. Cousens, "There is a cure for diabetes: the tree of life 21 day programs," California: North Atlantic Books, pp. 191-192, 2008.

[4] R.S. Sultana, M.A. Bari, "In vitro Propagation of Karalla (Momordicacharantea Linn.) from nodal segment and shoot tip," Journal of Biological Sciences, (3), pp. 11341139, 2003.

[5] A. Paul, K. Mitter, S. Sen Raychaudhuri, "Effect of Polyamines in in vitro Somatic Embryogenesis in 


\section{International Journal of Science and Research (IJSR) \\ ISSN (Online): 2319-7064}

Index Copernicus Value (2013): 6.14 | Impact Factor (2014): 5.611

Momordicacharantia L.," Plant Cell Tissue and Organ Culture, (97), pp. 303-311, 2009.

[6] I. GurbuZ, C. Akyuz, B. Yesilada, S. Bilge, "Antiulcerogenic effect of Momordicric iorantia L. fruits on various ulcer models in rats," Journal of Ethno Pharmacology, (71), pp. 77-82, 2000.

[7] P. Scm-tezzini,, B. Speroni, "Review on some plants of Indian traditional medicinewith antioxidant activity," Journal of Ethano Pharmacology, (71), pp. 23-43, 2000.

[8] N. Beloin, M. Cbeassor, K. Akpagana, J .Hudson, K. Sousse, K. Koumaglo, J.T. Amason, "Ethnomodiciflal uses of Momordi cacharontia(Cucurbitaceee) in Toga and relation to its phytochemistry and biological activity" Journal Ethano Pharmacology, (96), pp. 49-55. 2005.

[9] A.H.Subratty, A. Gurib-Fakim, E. Mabomoodally, "Bitter melon: An exoticvegetable with medicinal values," Neu. Food Science, (35), pp. 143-147, 2005.

[10] M.Y. Liauw, F.A. Natan, P. Widiyanti, D. Ikasari, N. Indraswati, F.E. Soctaredjo, "Extraction of Neem oil (Azachirachta indica A. Juss) using n-hexane and ethanol: studies on oil quality, kinetic and thermodynamic," ARPN Journal of Engineering and Applied Sciences, 3(3), 2008.

[11]H. Topallar, U. Gecgel, "Kinetics and thermodynamics of oil extraction from sunflower seeds in the presence of aqueous acidic hexane solutions, ${ }^{\text {e }}$ Turkish Journal of Chemical Engineering, (24), pp. 247-253, 2000.

[12] Octave Levenspiel, Book of „Chemical Reaction Engineering ${ }^{\text {ee }} 3^{\text {rd }}$ Edition, p.66, 2012.

\section{Author Profile}

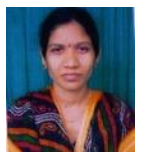

Uma Maheswari P. received her B.Tech degree in Chemical Engineering from Chaitanya Bharathi Institute of Technology, Hyderabad, in 2011 and M.Tech in the same discipline from JNTU College of Engineering, Anantapur, in 2006. She is currently working as a Lecturer on Ad-hoc basis at Chemical Engineering Department, JNTUACE, Ananthapuramu. Her areas of specialization are Adsorption and Pervaporation.

Dr. P. Dinesh Sankar Reddy received his M.Tech in Chemical Engineering from IIT Madras and Ph.D. Chemical Engineering from IIT Kanpur. He is working as an Assistant Professor at Chemical Engineering Department, JNTUACE, Ananthapuramu. His research interests include Interfacial Science \& Engineering and Environmental Science. 